\title{
The Sweep and Excitement of Science
}

\author{
JOHN R. PLATT, Ph.D.
}

$\mathrm{T}$ THE tremendous interest of the public in science today, I think, can be attributed to two main factors. One is the headline role that technology is now playing in war and in public affairs. It inspires readers to learn more, uniting their curiosity with good citizenship. But much of our fascination is also due to the skill and devotion of teachers and writers, editors, and broadcasters, who are trying to present the story of science to the mass audience and to explain in simple terms just how atomic piles, computers, and satellites work and what they mean. Interest feeds on explanations. The more we get, the more we want, from 4 years of age onward.

Science no longer needs to be explained just to laymen and citizens and children; it now needs to be explained to statesmen and philosophers and even to scientists themselves! The poor scientist can never keep up with the hundred thousand research papers that are published every year, and so he becomes a layman too, in every field but his own, and an important part of the mass audience. There will have to be writing up as well as writing down. There is a need and an audience at every level of sophistication from the nursery school to the graduate school.

What shall we give these audiences? Everyone has his own recipe, but I am sure we are all agreed today that quiz-show facts are not enough. I once heard an English chemist

Dr. Platt, professor of physics, University of Chicago, delivered the address from which this article was taken before the Thomas Alva Edison Foundation meeting on "The Mass Media and the Image of Science" in Washington, D.C., November 6, 1959. criticize another English chemist by saying, "That man knows more facts that are almost right than anyone else in the world." Perhaps the American public knows more facts that are almost right than any other public in the world.

But even if the facts are right, the public needs something larger if it is to understand what science is all about. There are three particular qualities of basic science-not technology but basic science-that $I$ think a citizen in a scientific society should be shown over and over until he begins to feel them for himself. The first quality is the excitement of science, the second is the sweep of science, and the third is the incompleteness of science.

\section{Excitement}

To say that basic science is exciting may sound like a contradiction. We are used to the really spectacular excitements of the engineers with their radar and rockets; and the life-and-death excitements of the doctors, the biological engineers, in their white coats. By contrast, the intellectual excitement of a man sitting over a microscope in a university basement tracking down a clue may seem pretty tame. But I would remind you that there are two intellectual excitements that are not tame at all and that we remember all our lives. One is the thrill of following out a chain of reasoning for yourself; the other is the pleasure of watching several strongly individualistic personalities argue about their deepest convictions. That is to say, the thrill of a detective story and the pleasure of watching a play by George Bernard Shaw. I would claim these are exactly the excitements basic science has to offer. 
Moreover these intellectual thrills in science are not something distant or alien, but something closely continuous with our everyday thinking. It is true that science is complex. This is because so many men have been building it up for so long. Nevertheless every individual step in it is a little inference as simple as looking out at the weather and deciding whether or not to take a raincoat. When we look at a celebrated rocket engineer like Werner von Braun, we see a man running a big complex organization and dealing with incredible horsepower. But when we look at a fundamental scientist like James Van Allen, the university professor whose tiny satellite equipment detected the radiation belts around the earth, fundamentally what we see is a man stepping to the door of his planet to see how the temperature is outside.

What is essential in any science story is the little chain of everyday inference, the reasoning. It may surprise many people to know that the chain of new scientific reasoning in a whole research study is frequently less complex than an everyday business decision or a crossword puzzle or a game of chess. It would have a salutary effect on our attitudes if for 24 hours we could cross out the words "science" and "scientist" wherever they appear, and put in their place the words "man reasoning." Even in the mathematical sciences, like physics, it is the reasoning that comes first, the equations second; and the equations will not save the theory if the reasoning is wrong. It cannot be said too often that science is not mathematics, but reasoning; not equipment, but inquiry.

The master at demonstrating reasoning to a mass audience was Conan Doyle. It would not be far wrong to think of every science story as his kind of detective story, with its puzzles and its suspense, its false leads and frayed tempers, and its brilliant Sherlock Holmeses, its halfbrilliant Inspector Lestrades, and its admiring Doctor Watsons. It is interesting to remember that Galileo himself used a very similar group of characters to explain his reasoning to a mass audience. Science is the greatest of all detective stories, a continued yarn that holds its audience for life, with the disagreements of the characters nowadays just as conspicuous and as amusing as ever.

The second excitement in the science story is the excitement of personalities. Biography and belles-lettres have hardly touched the field of science. There is valuable literary work to be done here. We need a good biography of G. N. Lewis, whose department at Berkeley turned out half of the best physical chemists in America. We need one of William Moffitt, the witty and brilliant theoretical chemist at Harvard, whose death last year at 33 was a loss far greater than the loss of any headlined baseball player or movie star. We need to put our senior teachers, James Franck of Chicago and Joel Hildebrand of California, and Percy Bridgman of Harvard, on Caedmon records, like poets, for posterity. There are many stories to be found in the sequences of brilliant teachers and brilliant pupils; my own department is fond of pointing out that three Nobel Prize winners this year and last got their Ph.D.'s with Fermi at the University of Chicago.

There is more unusual material, too, such as the story of the Hungarian-American scientists so brilliant that the others call them the "men from Mars." Or the story of such a man as Leo Szilard, a strange and contradictory thinker, who has surely influenced history by his unique role in starting the atomic bomb project as well as by his pioneer landmark papers in a dozen fields. The lighter material would include the amusing yarns that all scientists know about the hobbies of their favorite personalities. There are the mountain climbers; and Luiz Alvarez' parlor tricks; Richard Feynman's lockpicking; Arthur Roberts' musical compositions; and the insults, and the jokes-like the story of the Hungarian who had a sign over his desk that said "Being Hungarian is not enough."

And there are not only past stories, but future stories in the making, the men who may get the Nobel Prizes next year, and the year after.

When the stories of these personalities in science begin to be told, I suspect that we will find that all the men have one common characteristic: they are having fun. And the fun will be contagious. It has been said that the only peo- 
ple who get paid for doing exactly what they like are physicists and baseball players. When the word leaks out to the children, there will not be laboratories enough to hold the budding scientists.

\section{Sweep}

The second quality to get across to the mass audience is the scope or sweep of science. By this I mean the great range of problems covered, the range of the methods of work, and the wide range of the implications. For illustration I have selected three areas which show very different patterns of development today. One of these is biophysics, the second is what is called molecular biology, and the third is some of the recent work on evolution.

Biophysics is one of the border areas of physics. It is one of the active fronts that have radiated out from the atomic physics of 30 years ago. In one direction these fronts include the new and rich and spectacular sciences of space physics, nuclear physics, and solid state physics. In the other direction, the activity runs instead along several of the borderlines with the older disciplines, giving us the somewhat quieter fields of chemical physics, biophysics, and psychophysics, all of them largely confined to the university laboratories.

These latter areas are not sharply separated. I myself started out in chemical physics, studying the light absorption of dyes and similar molecules. I found that this led me to a study of chlorophyll which was a biological molecule and therefore biophysics. And then it led me to a study of the visual pigments of the human eye, which are the first elements struck by light in the psychological act of vision, and therefore psychophysics.

Biophysics proper is not what I call an exploding field at present but one that is just simmering along nicely. An important area of study lately has been the transfer of light energy between neighboring biological molecules. Many workers feel that such a transfer might be the first step in vision and the first step in photosynthesis, as well as the first step in the damaging of tissue cells by nuclear radiation. This makes it a hot subject and numerous international conferences on it are being held.
My only regret is that some people have chosen to call the subject "bioenergetics," which makes it sound more like a branch of naturopathy than a field of science.

Although the subject of energy transfer is of wide interest, the actual results are rather tenuous, partly because the experimental work has to be exceedingly painstaking. During a summing up session at the Brookhaven conference on this subject recently, the participants listed roughly a dozen new physical instruments and tools that they wished could be invented in order to facilitate work in this field. For example, methods are needed that would permit us to observe or infer the first chemical reaction steps of many biologically important molecules, including the primary molecules in vision, in photochemistry, in genetics, and the antibodies. Conceivably such methods of observation will evolve out of the fluorescence-interaction methods of Michael Kasha, or the tracer technique of Melvin Calvin, or the recent ingenious substitution technique of Engleberger and the Koshlands, or out of a completely new approach. The question remains open. Work is in progress.

Biophysics merges into a closely related area that today is anything but placid, the area of molecular biology. It has had an explosive development in the last 10 years. It was notable first for the numbers of physicists, chemists, and doctors attracted into it by such inspiring microbiologists as Salvador Luria and Max Delbruck. Now it is the scene of the last two Nobel Prizes in medicine, the one to Joshua Lederberg, George Beadle, and Edward Tatum, and one to Severo Ochoa and Arthur Kornberg. And sitting at conferences, one watches with pleasure and astonishment the beautiful demonstrations of the other theorists and experimenters, wondering which of them will be next to get the prize.

Will it be James Watson and F. H. C. Crick, with their two-strand model of the DNA molecule so thoroughly proved in the last few years? Will it be Meselson and Stahl, or Taylor, Woods, and Hughes, with their beautiful tracer methods of testing the model? Will it be Seymour Benzer, with his analysis of microgenetic characters a thousand times finer than any ever 
examined before? Will it be Cy Levinthal or some of his competitors, racing to see who can crack the great cryptogram, the code that translates the DNA molecule into the other cell materials? Or Theodore Puck, with his method of culturing perfect tissue cells? Or Albert Coons, with his fluorescent method of labeling antibodies?

The shrewdness of such men in reasoning and experiment has brought a new atmosphere to biology. Needless to say, the older scientists are not entirely sympathetic. Oversimplification, they snort. One eminent gentleman said, and I quote: "You know there are scientists, and there are people in science who are not doing science at all. We need their auxiliary work-they build apparatus, they make minor studies-but they are not scientists."

To which the young microbiologist replies: "Well, there are two kinds of biologists, those who are looking to see if there is one thing that can be understood, and those who keep saying it is very complicated and that nothing can be understood."

Sixty years ago when Pasteur was also trying to see if there was one thing that could be understood, the audience hung breathless on his results. I think this could happen again today. At any rate, molecular biology is, next to nuclear physics, the most intellectually exciting field for a young person to enter at the present time.

A third area, still more biological, is that of the recent work on evolution discussed at the Darwin Centennial Celebration this past fall at the University of Chicago. This celebration honored the 100th anniversary of publication of "Origin of Species." Several of the papers offered dramatic new illustrations of the Darwinian principle of evolution. One of these by Nicholas Tinbergen demonstrated that it is not just bones and muscles that evolve but also behavior, and he gave numerous examples of such evolution as found in the behavior of birds that nest in cramped and dangerous places.

In another paper, F. Clark Howell and Sherwood Washburn showed from the study of old skulls that man's brain has increased in size rapidly since he began using tools and fire, and is now almost three times as large as it was then. Another study, by Cesare Emiliani, showed that this evolution of our brains may have taken a time much shorter than anyone has supposed, only a few hundred thousand years according to new geological dates. In short, intelligent man, as we know him, may have developed with dramatic suddenness as a result of using his hands to manipulate the world around him. Perhaps we are still developing at the same remarkable rate. It was better brains that determined which of the mancreatures would survive then; and it is better brains that will help us to survive now, we hope.

At the Darwin conference there was also much said about man's population problem today, which is a terribly timely aspect of evolution. There was something like a three-cornered debate on population, between the grandson of the founder of evolution, Sir Charles Darwin; the biologist, Sir Julian Huxley; and another Nobel Prize winner, H. J. Muller. Darwin says that in 50 to 100 years, the overcrowding of our increased population will destroy our civilization forever, and cannot be reversed, because people and groups who want to have many children will go on having them, whether it is good for the whole community or not. Huxley is more optimistic and thinks the population explosion can be stopped if we are intelligent enough to find incentives for stopping it. And Muller says that it is already urgent for us to take really dramatic steps, that is, to begin selective breeding, if we want civilization as we know it to continue.

All three men are united as scientists in saying that we are doomed if we do nothing to reduce our birth rates; they differ only in how much they think, as hopeful men, that we can do nationally and internationally about the problem. Many people may not approve of scientists offering to give their scientific knowledge and counsel to human affairs in this way, just as many people did not approve of the theory of evolution itself a century ago. But I think that the reporter who has the courage to try to transmit this population debate to the public in a full and fair way may find that he has a story as exciting, as controversial, and finally as important to history, as the debate over evolution itself ever was. 


\section{Incompleteness}

The intelligent layman should be told of a third quality, the incompleteness of science.

All science has gaps in it. The most familiar are the inevitable small gaps, the data that one could still go on taking, the unexamined minor assumptions, or the unresolved questions. Most of these do not bother us because we realize that a scientific age is an age of tentative conclusions and working rules that may well have to be changed later. Yet it is important for us to emphasize this incompleteness, especially to the young, because they have hopes and aspirations and they want an open-ended story, with something left for them to do when they finally take our places.

What is not so often realized is that science is incomplete in more serious ways, with gaps that scientists themselves, tied to their own narrow specialties, hardly realize the existence of. In some ways, for all its diversity, science is narrower now than it has ever been before. Few of the men who work on photosynthesis know anything about physics; few of the men who work on nervous tissue know any organic chemistry; few of the men who work on the brain have any understanding of the mind. There are exceptions. An Enrico Fermi or Edward Teller or Harold Urey can work on stars or nuclei or molecules, just as his fancy strikes him. A John von Neumann can work on quantum mechanics as well as the theory of games. A Percy Bridgman can work on solids as well as logic. But for every such man, there are hundreds who spend their lives repeating the kind of experiments they did for their doctor's degree.

Even the intellectual leaders are blind to some fields. For over a century, some of the greatest physicists, Young and Maxwell and Helmholtz and Schrodinger, thought it of the greatest importance to study human visual perception. Today, I daresay not one of the twenty leading physicists in this country would have even a casual interest in this subject. Likewise, interest in the philosophy of physics has dropped almost to zero among the bright young men; yet this field may simply be waiting for a new Ernst Mach who will stir it up and pave the way for another revolution like relativity. And we have all noticed such blind spots in the more technical fields, where it has suddenly been discovered, for example, how badly everyone has been neglecting oceanography, an area perhaps of central importance for our future food and resources.

I think these gaps cry out for reviewers and critics broadly trained and broadly read, who are competent to see what the neglected areas are and to encourage the young to go into them. A balanced and vigorous science requires a balanced and vigorous criticism. To paraphrase Clemenceau's remark that war is too important to be entrusted to generals, science is too important to be left to the scientists. Intelligent outside evaluation is good for a department, it is good for a university, and it would be good for science itself. The incompleteness of science is a challenge to great criticism. It is a challenge which I think will be met in the very finest presentations of science to the public.

\section{The Life of Man}

It is a thrilling thing to be participating as actor or observer in the scientific revolution of our times, as science enters and transforms the life of man. Some are depressed by the hard work that must be done to make a world, and by the constant threat of failure and catastrophe. Some say philosophy has failed. I think this is only a momentary lapse between the old philosophy and the new that rises already in the laboratories. I think this century marks in history a revolution in man's outlook even more profound, if possible, than the accompanying revolution in science and technology. Man has suddenly found himself. He has explored all the earth and stepped outside it. He taps the sun's source of energy and stands ready to manipulate the weather and use the oceans. He measures back to the beginnings of time and out to the ends of space and sees his own sudden emergence, a thinking creature spun out of light and air and water and holding power in his hand, yet probably only one of millions of such creatures on other worlds.

And the power man holds is not only technical power but something far greater still, evolutionary power. He creates new species of plants and animals, halts or speeds up evolution, ma- 
nipulates heredity like chemistry, and prepares to turn his own flimsy organism into whatever fantastic and brilliant and powerful form he most desires. The whole future is open-ended, waiting for us. This is not a time of philosophical decay but a time of birth. In the midst of our worry and fear, man reasoning, man the creator, is about to be born. The old philosophies will burst off and blow away, unable to contain so fierce a fire. From now on, in every century, man will look back and say, this was the one.

When we speak of the sweep and excitement of science, we are speaking of the cradle of man.

\section{PUBLICATION ANNOUNCEMENTS}

Address inquiries to the publisher or sponsoring agency. WHO publications may be obtained from the Columbia University Press, Inter. national Documents Service, 2960 Broadway, New York $2 \%$, N.Y.

The Health of People Who Work. Edited by Albert Q. Maisel. 1960; 268 pages; \$4.50. National Health Council, Publications Department, 1790 Broadway, New York 19.

An Examination of the Concept of Preventive Medicine. Health Information Foundation Research Series 12. By Odin W. Anderson, Ph.D., and George Rosen, M.D., Ph.D. $1960 ; 22$ pages. Health Information Foundation, 420 Lexington Ave., New York 17.

Bureau of Applied Social Research. A report on the year 1958-59. February $1960 ; 19$ pages. Bureau of Applied Social Research, Columbia University, 605 West 115th Street, New York 25.

Venereal Disease. Old Plague-New Challenge. Public Affairs Pamphlet No. 292. By T. Lefoy Richman. January 1960 ; 20 pages; 25 cents. Public Affairs Pamphlets, 22 East 38th Street, New York 16.

Cigarettes and Health. Public Affairs Pamphlet No. 220A. By Pat McGrady. March 1960; 20 pages; 25 cents. Public Affairs Pamphlets, 22 East 38th Street, New York 16.

The Federal and Provincial Health Services in Canada. Edited by $\mathbf{R}$. D. Defries, O.B.E., M.D., D.P.H., I.L.D., Dr.P.H. 1959 ; 147 pages. Canadian Public Health Association, 150 College St., Toronto, Ontario.
Let's Use, Not Abuse Health Insurance. Leaflet. American Medical Association, 535 North Dearborn St., Chicago 10, Ill.

National Science Foundation Programs for Education in the Sciences. NSF-59-6. March 1959; 27 pages. National Science Foundation, 1951 Constitution Ave., Washington, D.C.

Sigerist on the History of Medicine. Edited by Felix Marti-Ibanez, M.D. April 1960; $\$ 6.75$; 313 pages. MD Publications, Inc., 30 East 60th Street, New York 22.

An Introduction to Public Health. By H. S. Mustard, M.D., LL.D., and E. L. Stelbbins, M.D. 1959; 338 pages with index. Macmillan Co., New York.

\section{World Health Organization}

Effect of Radiation on Human Heredity: Investigations of Areas of High Natural Radiation. WHO Technical Report Series No. 166. 1959 ; 30 cents ; Geneva.

Requirements for Biological Substances. 1. General Requirements for Manufacturing Establishments and Control Laboratories. 2. Requirements for Poliomyelitis Vaccine (Inactivated). Report of a study group. WHO Technical Report Series No. $178.1959 ; 30$ cents ; Geneva.

Requirements for Biological Substances. 3. Requirements for Yellow Fever Vaccine. 4. Requirements for Cholera Vaccine. Report of a study group. WHO Technical Report Series No. 179. 1959; 30 cents ; Geneva.
Requirements for Biological $\mathbf{S u b}$ stances. 5. Requirements for Smallpox Vaccine. Report of a study group. WHO Technical Report Series No. $180.1959 ; 30$ cents; Geneva.

Epidemiology of mental disorders. Eighth report of the Expert Committee on Mental Health. WHO Technical Report Series No. 185. 1960 ; 30 cents; Geneva.

Appraisal of Fellowships. Report of a study group. WHO Technical Report Series No. 186. 1960; 30 cents ; Geneva.

Expert Committee on AddictionProducing Drugs. Tenth report. WHO Technical Report Series No. 188. 1960; 30 cents ; Geneva.

Expert Committee on Leprosy. Second report. WHO Technical Report Series No. 189. 1960 ; 30 cents ; Geneva.

\section{WHO Public Health Papers}

Psychiatric Services and Architecture. Prepared jointly by three WHO consultants. 1959 ; 60 cents ; Geneva.

Epidemiological Methods in the Study of Mental Disorders. Report by D. D. Reid, M.D., D.Sc., M.R.C.P. 1960; $\$ 1$; Geneva.

Health Services in the U.S.S.R. Prepared by participants in a study tour organized by the World Health Organization. 1960 ; 60 cents ; Geneva.

(With the above three "Public Health Papers" WHO launches a new series designed to stimulate international thinking, discussion, and planning by the publication of personal ideas; observations, and suggestions of individuals or groups.) 